\title{
Graphene Oxide Reinforced Polycarbonate Nanocomposite Films with Antibacterial Properties
}

\author{
R. Mahendran, ${ }^{1}$ D. Sridharan, ${ }^{1}$ K. Santhakumar, ${ }^{2}$ T. A. Selvakumar, ${ }^{3}$ \\ P. Rajasekar, ${ }^{3}$ and J.-H. Jang ${ }^{2}$ \\ ${ }^{1}$ Department of Chemistry, Anjalai Ammal Mahalingam Engineering College, Anna University, Kovilvenni 614 403, India \\ ${ }^{2}$ School of Information and Communications and WCU Department of Nanobio Materials and Electronics, \\ Gwangju Institute of Science and Technology, Gwangju 500-712, Republic of Korea \\ ${ }^{3}$ Department of Biotechnology, Rajalakshmi Engineering College, Anna University, Thandalam, Chennai 602 105, India
}

Correspondence should be addressed to R. Mahendran; anishmahendran10@gmail.com

Received 17 March 2016; Revised 1 June 2016; Accepted 1 June 2016

Academic Editor: Subrata Kundu

Copyright (C) 2016 R. Mahendran et al. This is an open access article distributed under the Creative Commons Attribution License, which permits unrestricted use, distribution, and reproduction in any medium, provided the original work is properly cited.

\begin{abstract}
The incorporation of carbonaceous nanofillers into polymers can result in significant materials with improved physicochemical properties and novel composite functionalities. In this study, we have fabricated antibacterial, lightweight, transparent, and flexible graphene oxide (GO) reinforced polycarbonate thin films by a facile and low-cost methodology. Solution blending is employed to get a homogeneous mixture of PC-GO composites at various loading of GO, and the thin films are prepared by dry-wet phase inversion technique. Thermal studies and micrographs of the films revealed the incorporation of GO in PC matrix. Microstructure of the thin films showed the homogeneous dispersion of GO at micro- and nanoscales; however, at higher loading of GO (0.7\%), significant agglomeration is observed. More importantly, PC-GO composite films exhibited excellent antibacterial activities against E. coli and S. aureus, owing to the antibacterial nature of GO nanoparticles.
\end{abstract}

\section{Introduction}

Antibacterial nanomaterials possess the ability to inhibit/ destroy the growth of the bacteria; hence, they are effectively used in biomedical devices, biomechanics, and tissue engineering applications [1]. Notably, the antibacterial nanomaterials are applied to inhibit bacterial infection in implanted medical devices, since the bacterial infection can cause device failure and tissue destruction [2]. Conventionally, silver nanoparticles are being used as antibacterial materials in biomedical devices; however, they have certain drawbacks such as high cost, scalability, toxicity to the environment, and problems in disposal of the wastes [3]. Recently, graphene and its derivatives have attracted increasing attention in making antibacterial materials owing to their excellent antibacterial activities against bacteria $[4,5]$. However, large surface area and strong van der Waals force among the graphene sheets make significant agglomeration in the polymer matrix and the powdery form protects their practical applications [6, 7]. Furthermore, the aromatic nature of the $\mathrm{C}-\mathrm{C}$ bond of the graphene makes them chemically stable and inert [8]. These drawbacks could be overcome by using functionalized graphenes, particularly graphene oxide (GO), which possesses oxygen functionalities (carboxyl, hydroxyl, and epoxy groups) and is well dispersed in water and some organic solvents $[9,10]$.

Recently, the GOs have been validated as a potential candidate for killing Gram-negative (E. coli) and Grampositive (S. aureus) bacteria $[4,7,11-15]$. Owing to their excellent antibacterial nature, the reinforcement of the GOs in a polymer matrix not only enhances the antibacterial nature of the pristine polymer but also improves the mechanical, thermal, and chemical stabilities significantly [16, 17]. In addition, the hydrophilic functional groups (hydroxyl, carboxylic, and epoxy groups) of GO could be used to make homogeneous dispersion and proper alignment of GO in the 
polymer matrix [17]. All of these outstanding traits make the $\mathrm{GO}$ an ideal candidate for blending with polymers to improve the antibacterial nature of the host polymers.

Polycarbonate (PC), an engineered thermoplastic polymer, possesses excellent temperature resistance, optical transparency, high impact strength, good optical properties, and dimensional stability [18]. Hence, it is widely used in automotive industry, components of aircraft, electronics, data storage, and biomedical devices such as hemodialyzers, drug delivery carriers, blood oxygenators, and arterial filters [19]. However, PCs have certain drawbacks such as less antibacterial activities, stress cracking, low scratch resistance, high sensitivity to abrasive cleaners, and ability to deteriorate in many organic solvents $[18,19]$. Generally, the PC's antibacterial activity is being enhanced by functionalizing reactive groups/blending with other antibacterial materials [20-23].

In this study, we report a facile, low-cost, and scalable technique for the fabrication of PC-GO nanocomposites to achieve homogeneous dispersion of $\mathrm{GO}$ in the polymer matrix and make strong interactions between PC and GO at the molecular level. In addition, weak hydrogen bonding between the oxygen-containing functional groups of $\mathrm{GO}$ and carbonyl groups of the PC could make strong interaction between them. The incorporation of GO in the PC matrix was substantiated by thermal analysis and SEM micrographs. Furthermore, we have investigated the antibacterial activity of PC-GO, PC, and GO against S. aureus and E. coli. To the best of our knowledge, the antibacterial studies of GO reinforced $\mathrm{PC}$ nanocomposite thin films have not yet been reported for tissue engineering applications.

\section{Materials and Methods}

2.1. Materials. Bisphenol A polycarbonate (PC) was supplied by GE Plastic Ltd., India, and was dried at $100^{\circ} \mathrm{C}$ in an oven for $6 \mathrm{~h}$ prior to use. Graphene oxide was prepared from graphite flakes via modified Hummer's method [24]. Dimethyl formamide (DMF) was purchased from SigmaAldrich, India, and used as received and distilled water was used as coagulant.

2.2. Fabrication of $P C$ and $P C-G O$ Thin Films. The $P C$ and $\mathrm{PC}-\mathrm{GO}$ thin films were prepared by dry-wet phase inversion technique [25-27]. Figure 1 shows the schematic representation of the fabrication of PC-GO nanocomposites. Briefly, the PC (20 wt\%) was dissolved in DMF and stirred for $5 \mathrm{hrs}$ at $60^{\circ} \mathrm{C}$ by magnetic stirring to obtain a homogeneous solution. Consequently, the GO was dispersed in DMF by ultrasonication for $2 \mathrm{~min}$, followed by mechanical agitation for $5 \mathrm{hrs}$. The GO dispersion was mixed with the PC solution and stirred for $7 \mathrm{hrs}$ at $50^{\circ} \mathrm{C}$ to obtain a homogenous solution. For fabricating thin films, the PC-GO solution was poured on a glass plate and cast by a casting knife (thickness: $50 \mu \mathrm{m}$ ) at room temperature. The nascent film was kept on a hot plate $\left(80^{\circ} \mathrm{C}\right)$ to evaporate the solvent for $90 \mathrm{~s}$ and dipped in a coagulation (deionized water) bath to leach out the film from the glass plate. The film was placed in a coagulation bath for

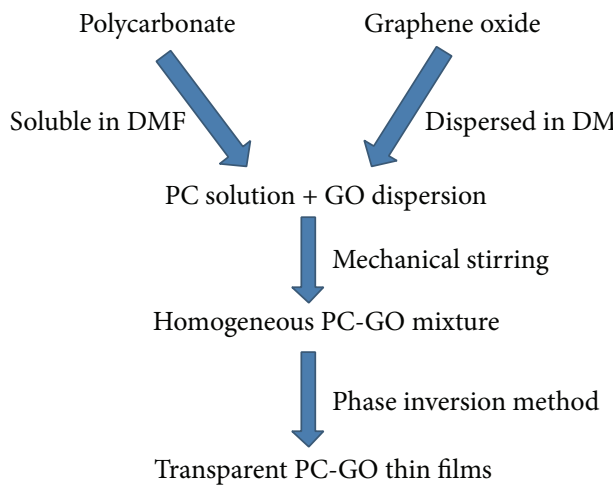

FIGURE 1: Schematic representation for fabrication of PC-GO thin films.

$3 \mathrm{hrs}$ and then dried in an oven at $80^{\circ} \mathrm{C}$ for $5 \mathrm{hrs}$ to remove the residual water.

2.3. Characterizations. Fourier Transform-Infrared Spectroscopy (FT-IR, Perkin Elmer, Spectrum RX I) was carried out for GO, PC, and PC-GO 3 nanocomposite over the wave number range of $4000-500 \mathrm{~cm}^{-1}$. Thermogravimetric analysis (TGA/SDTA851e, Mettler Toledo) of the GO, PC, and PC-GO 3 nanocomposite was carried out from room temperature to $1000^{\circ} \mathrm{C}$ at $10^{\circ} \mathrm{C} / \mathrm{min}$ under nitrogen atmosphere, to conclude the incorporation of GO in the PC matrix. The transparency of the pristine PC and PC-GO composites was measured using UV-Vis-NIR spectrophotometer (UVVis-NIR, Cary 5000). Raman Spectrometer (model: T64000, HORIBA Jobin Yvon, France) was employed to characterize the GO, PC, and PC-GO 3 samples over the wave number range of $500-3500 \mathrm{~cm}^{-1}$.

2.4. Morphological Studies. The surface and cross-sectional microstructures of the PC and PC-GO 1, PC-GO 2, PC-GO 3, and PC-GO 4 nanocomposite films were examined by Field Emission-Scanning Electron Microscopy (FE-SEM, Hitachi, S-4700) to analyze the dispersion and agglomeration of GO in the PC matrix. For the analysis, the thin film was dipped in liquid nitrogen for 20-25 s and then fractured. A thin layer of gold was coated on the thin film's top surface and cross section using a gold sputter coating device.

2.5. Evaluation of Antibacterial Activities. The antibacterial activities of the PC, GO (10 mg, powdery form), and PC-GO 3 nanocomposite were assessed using E. coli (Gram-negative) and S. aureus (Gram-positive) by Disc Diffusion method (Kirby Bauer test) [28, 29]. For the analysis, the medium was sterilized at $120^{\circ} \mathrm{C}\left(15 \mathrm{lb} / \mathrm{in}^{2}\right)$. About $30 \mathrm{~mL}$ of the Müller Hinton Agar (MHA) medium was transferred aseptically into sterilized Petri plates and kept at $37^{\circ} \mathrm{C}$ for solidification. The bacterial strains were spread over the Petri plates using Lrod. The powdery forms of GO, PC, and PC-GO films were placed on the media containing E. coli and S. aureus cultures, individually, and incubated for $24 \mathrm{~h}$ at $37^{\circ} \mathrm{C}$. The inhibition zones of the samples were identified and captured. 


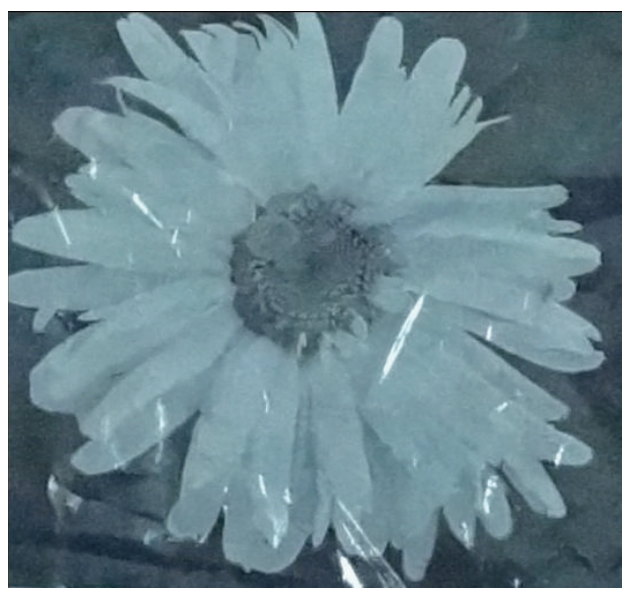

(a)

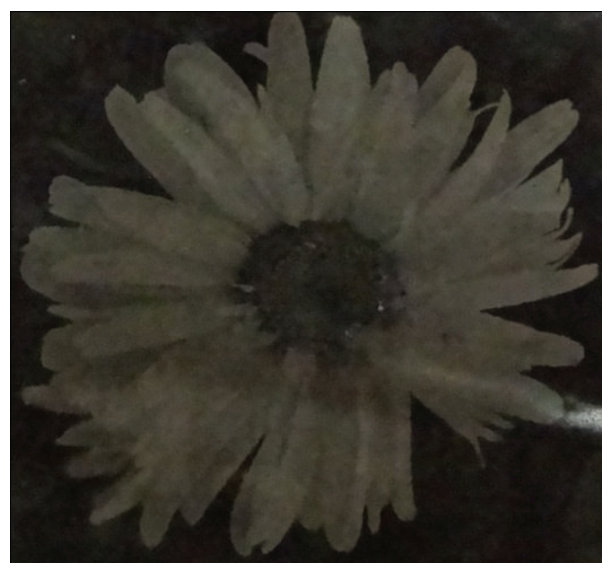

(c)

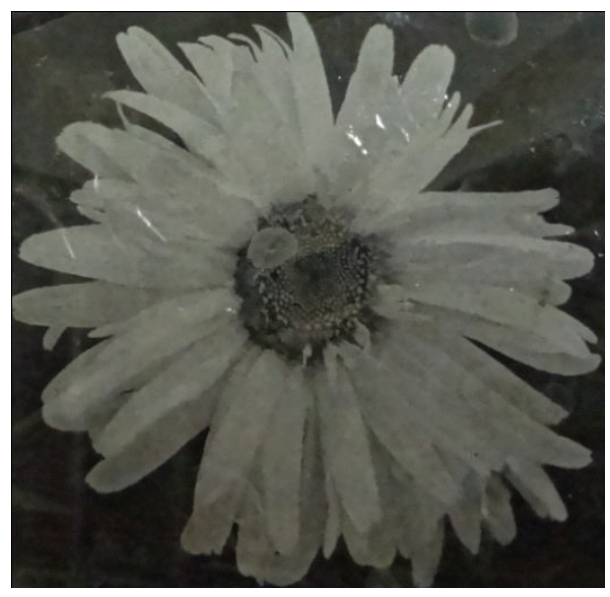

(b)

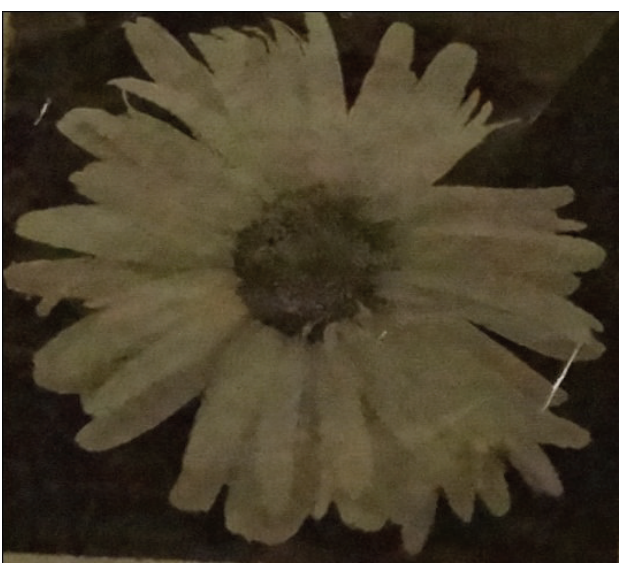

(d)

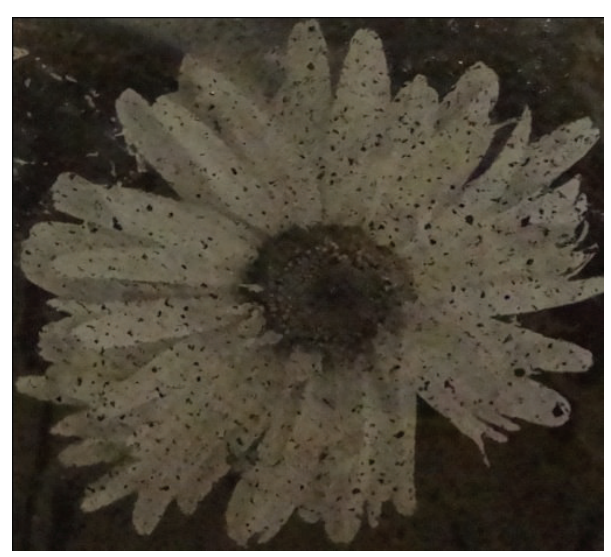

(e)

FIgUre 2: Photographs of PC (a) and PC-GO 1, PC-GO 2, PC-GO 3, and PC-GO 4 (b-e) nanocomposite thin films.

\section{Results and Discussion}

3.1. Transparency of $P C$ and $P C-G O$ Thin Films. Figure 2 shows the images of the PC and PC-GO 1 (0.1wt\%), PCGO 2 (0.3 wt $\%)$, PC-GO 3 (0.5 wt $\%)$, and PC-GO 4 (0.7 wt $\%)$ (for convenience, nanocomposites thin film compositions are denoted by PC-GO 1, PC-GO 2, PC-GO 3, and PC-GO 4, resp.) nanocomposite transparent films, which changed in color from lighter to darker (black color) with respect to the loading of GO in the PC matrix; at higher loading of GO (0.7 wt $\%)$, the darkest and more agglomerated film was obtained (Figure 2(e)). This might be due to the visible region absorption of $\mathrm{C}=\mathrm{C}$ bonds in the $\mathrm{GO}$, owing to the average number of $\mathrm{C}=\mathrm{C}$ double bonds being increased by increasing 
TABle 1: Composition of PC and PC-GO 1, PC-GO 2, PC-GO 3, and PC-GO 4 nanocomposites.

\begin{tabular}{lcccc}
\hline Thin film code & PC $(\mathrm{wt} \%)$ & GO $(\mathrm{wt} \%)$ & Transparency $(\%)$ & 92 \\
PC & 20 & 0 & 89 & 17 \\
PC-GO 1 & 20 & 0.1 & 88 & 19 \\
PC-GO 2 & 20 & 0.3 & 85 & 25 \\
PC-GO 3 & 20 & 0.5 & 81 & 25 \\
PC-GO 4 & 20 & 0.7 & & 28 \\
\hline
\end{tabular}

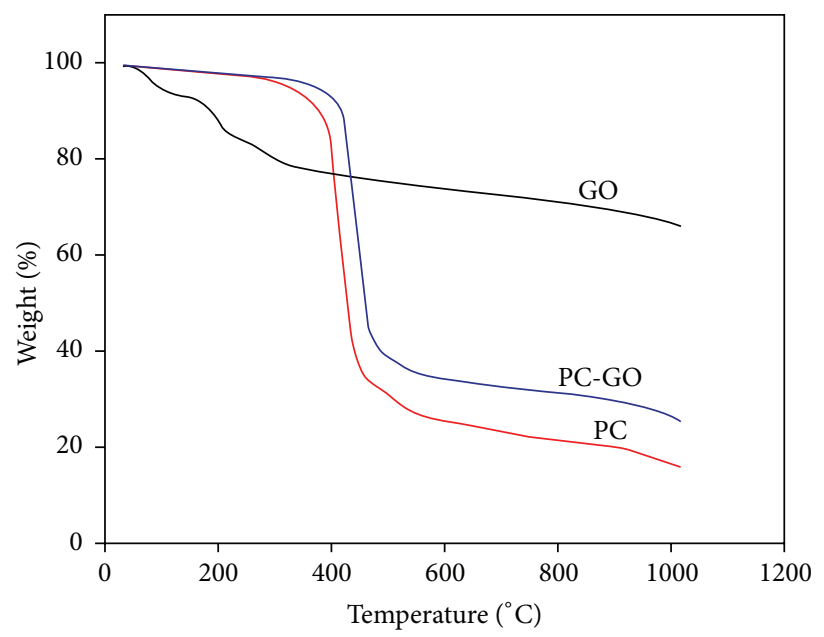

Figure 3: Thermogravimetric analysis of PC, GO, and PC-GO 3 composite.

the concentration of GO [30]. Table 1 shows the composition of PC and PC-GO 1, PC-GO 2, PC-GO 3, and PC-GO 4 nanocomposites and thickness of the as-prepared thin films. The thicknesses of the PC and PC-GO thin films were clearly measured by using Digimatic Micrometer (Mitutoyo, Series 293 MDC-MX Lite) and the FE-SEM images. The thickness of the PC-GO 1, PC-GO 2, PC-GO 3, and PC-GO 4 thin films minutely increased with respect to the content of GO in the polymer matrix.

3.2. Thermal Studies. Thermogravimetric analysis of the PC, $\mathrm{GO}$, and $\mathrm{PC}-\mathrm{GO}$ composite is represented in Figure 3. In the $\mathrm{GO}$, the weight loss around $100^{\circ} \mathrm{C}$ was caused by the elimination of water molecules and gradual reduction from $130^{\circ} \mathrm{C}$ to $210^{\circ} \mathrm{C}$. Further, the weight loss of the GO extended to $600^{\circ} \mathrm{C}$. The major mass reduction was observed at $210^{\circ} \mathrm{C}$ due to the decomposition of the oxygen-containing functional groups [31]. The PC was thermally stable up to $280^{\circ} \mathrm{C}$ and its maximum degradation temperature was observed at $380^{\circ} \mathrm{C}$ (decomposition of PC backbone) [32]. The PC-GO composite was degraded by two stages: the initial weight loss started at $210^{\circ} \mathrm{C}$ due to the loss of oxygen functionalities of the GO. In the second stage, the weight loss started at $380^{\circ} \mathrm{C}$, due to the decomposition temperature of the $\mathrm{PC}$ backbone. The weight loss around $210^{\circ} \mathrm{C}$ concludes the confinement of the GO in the polymer matrix. Hence, the reinforcement of GO in the PC matrix was clearly validated by thermogravimetric analysis.

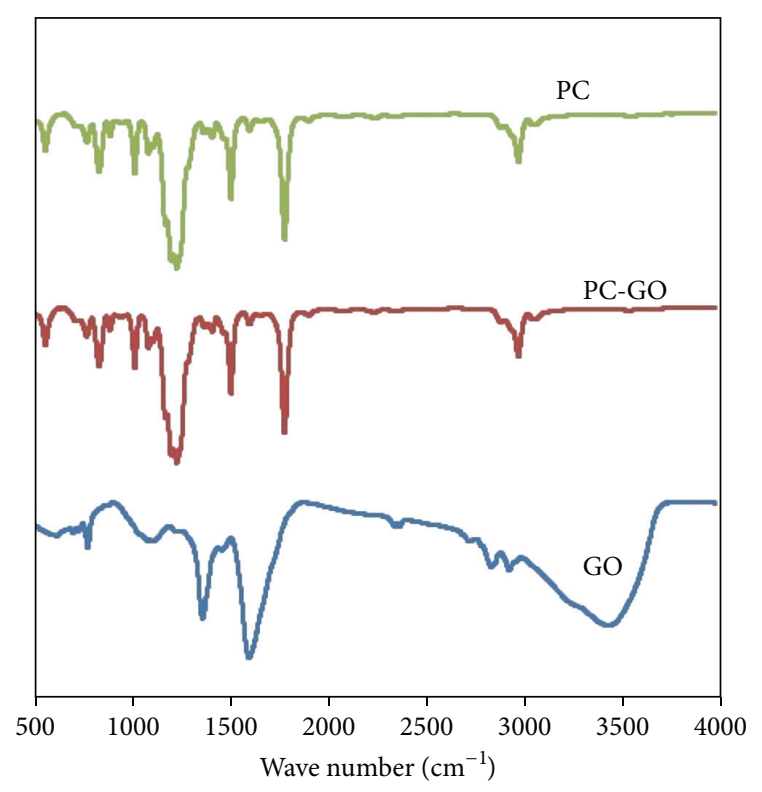

FIgURE 4: FT-IR spectra of GO, PC, and PC-GO 3 composite.

3.3. Fourier Transform-Infrared (FT-IR) and Raman Spectroscopy. FT-IR spectra of the PC, GO, and PC-GO composite are shown in Figure 4. In the GO, the peaks appeared at 


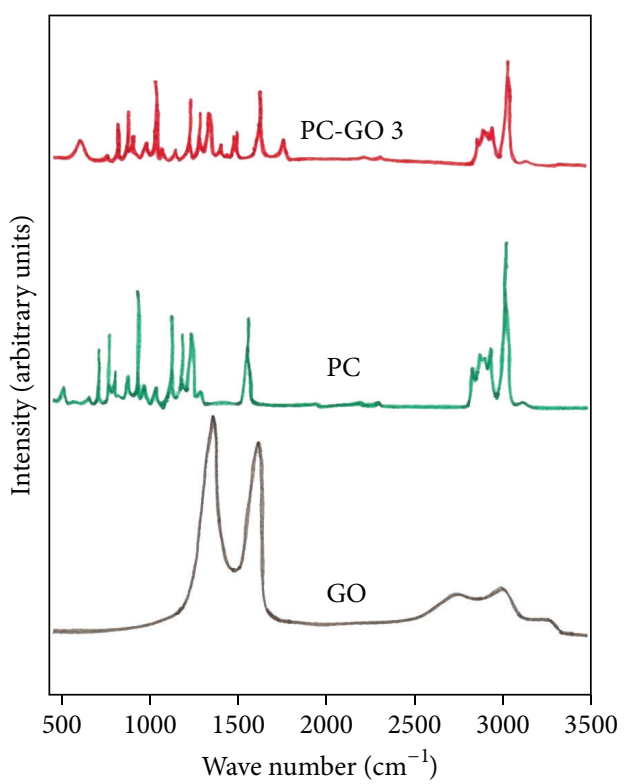

FIgURE 5: Raman spectra of GO, PC, and PC-GO 3 composite.

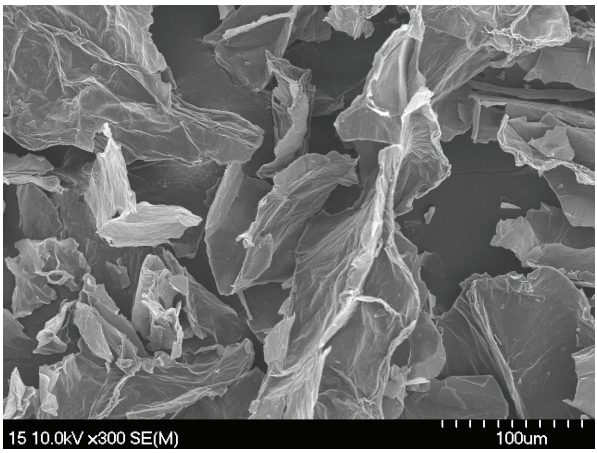

(a)

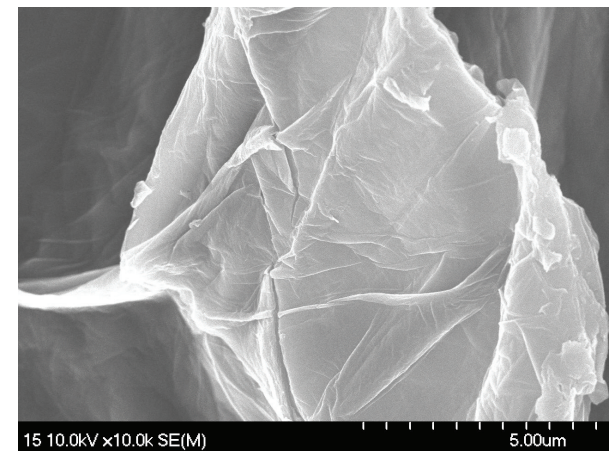

(b)

FIGURE 6: SEM micrographs of as-prepared graphene oxides at different magnifications (a and b).

$1720,1630,3400$, and $1220 \mathrm{~cm}^{-1}$ attributed to $\mathrm{C}=\mathrm{O}, \mathrm{C}=\mathrm{C}, \mathrm{O}-$ $\mathrm{H}$, and $\mathrm{C}-\mathrm{O}$ (epoxy), respectively [33]. In pristine $\mathrm{PC}$, the strong absorption bands due to the $\mathrm{C}=\mathrm{O}$ stretching vibration of the carbonate group were observed at $1,780 \mathrm{~cm}^{-1}$ for diphenyl dicarbonates [34]. The absorption bands of the C$\mathrm{O}-\mathrm{C}$ stretching vibrations were also identified at the range $1150-1270 \mathrm{~cm}^{-1}$. Further, $\mathrm{C}=\mathrm{O}$ and $\mathrm{C}-\mathrm{H}$ stretching of methyl groups peaks were observed at $\sim 1770 \mathrm{~cm}^{-1}$ and $\sim 3100 \mathrm{~cm}^{-1}$, respectively.

Figure 5 shows the Raman spectra of the GO, PC, and PC$\mathrm{GO}$ composite. In the $\mathrm{PC}$ spectra, $\mathrm{C}-\mathrm{H}$ stretching vibration appears in the range of $3000-2843 \mathrm{~cm}^{-1}$, C-O symmetrical stretching at $1608 \mathrm{~cm}^{-1}, \mathrm{C}-\mathrm{O}-\mathrm{C}$ vibration at $1248 \mathrm{~cm}^{-1}$, and $\mathrm{C}-\mathrm{H}$ bending vibration at $830 \mathrm{~cm}^{-1}$. In the $\mathrm{GO}$ spectra, $\mathrm{G}$ band was observed at $\sim 1590 \mathrm{~cm}^{-1}$ and $\mathrm{D}$ band appeared at $\sim 1350 \mathrm{~cm}^{-1}$. In the PC-GO spectra, slight shifting of the characteristics of $G$ and $D$ bands was observed at $\sim 1600 \mathrm{~cm}^{-1}$ and $\sim 1390 \mathrm{~cm}^{-1}$, respectively. Further, the intensity decreased due to low concentration of the GO in the polymer matrix [35, 36].

3.4. Morphological Analysis. FE-SEM was carried out to explore the agglomeration and dispersion of GO in the PC matrix. Figures 6(a) and 6(b) show the as-prepared GO nanoflakes at low and high magnifications. The micrographs also indicate that the GO has ultrathin lamellar structure at micro- and nanolevels, and the GO has well defined porous network and interlinked three-dimensional structure [37].

Figures 7(a)-7(e) depict the SEM images of the surface of pristine PC and PC-GO 1, PC-GO 2, PC-GO 3, and PCGO 4 thin films. The thicknesses of the PC and PC-GO 4 thin films were $17 \mu \mathrm{m}$ and $28 \mu \mathrm{m}$, respectively. The surface roughness of the membranes slightly increased with respect to the GO content ( 0 to $0.7 \mathrm{wt} \%$ ), which was clearly identified from Figures 7(a)-7(e). Notably, the agglomeration of GO in the PC matrix can be clearly observed from the large 


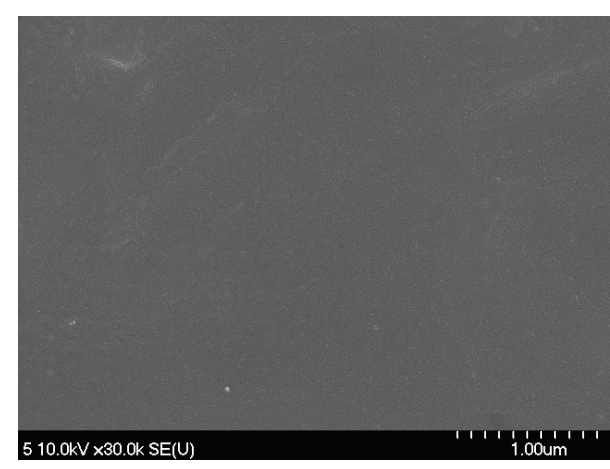

(a)

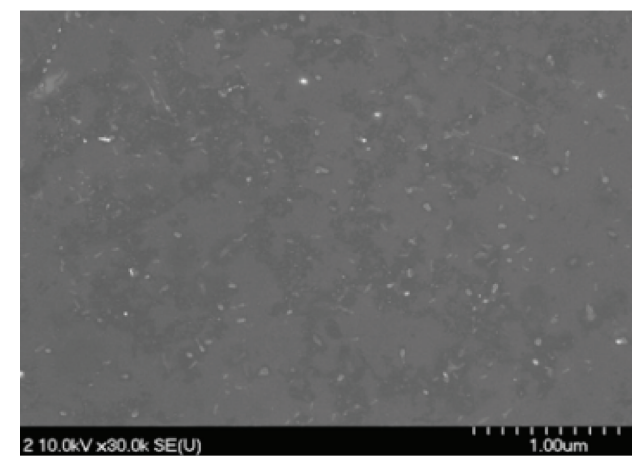

(c)

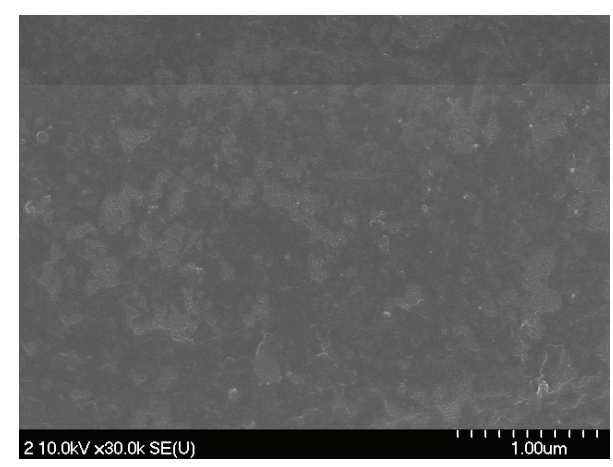

(b)

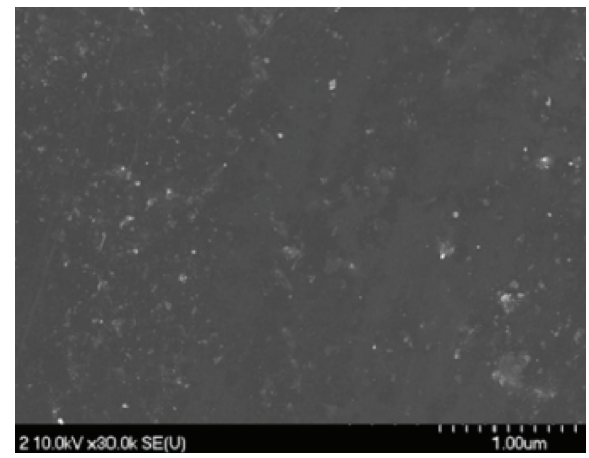

(d)

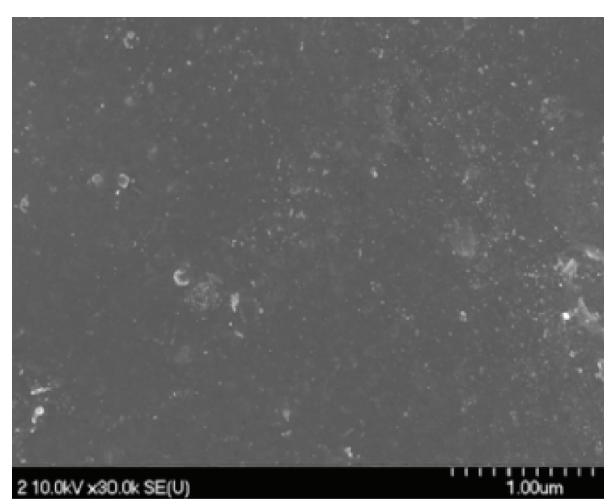

(e)

FIGURE 7: SEM micrographs: surface morphology of PC (a) and PC-GO 1, PC-GO 2, PC-GO 3, and PC-GO 4 (b-e) thin films.

and irregular grains on the surface of the thin films by increasing the concentration of the GO. These grains may have formed because of the aggregation of GO molecules on the surface of the PC films, which might be due to the weak intermolecular hydrogen bonding between the oxygencontaining functional groups $(-\mathrm{OH}$ and $-\mathrm{COOH})$ of $\mathrm{GO}$ and the carbonyl $(-\mathrm{C}=\mathrm{O})$ group of $\mathrm{PC}$.

The cross-sectional morphologies of the PC and PC-GO 1, PC-GO 2, PC-GO 3, and PC-GO 4 thin films are shown in Figures 8(a)-8(e). It was observed that the cross section of the PC matrix exhibits negligible roughness compared with the PC-GO 1, PC-GO 2, PC-GO 3, and PC-GO 4 nanocomposites. Furthermore, the PC-GO 1, PC-GO 2, PC-GO 3, and PC-GO 4 thin films show a rough fracture with irregular protuberances, owing to the aggregation of $\mathrm{GO}$ sheets in the PC matrix. The layered structure of the GO was lucidly identified at the cross section of the PC-GO 1, PC-GO 2, PCGO 3, and PC-GO 4 thin films. In addition, the agglomeration of $\mathrm{GO}$ in the polymer matrix gradually increased along with the increasing weight ratio of GO in the PC matrix. Notably, the GO nanoflakes in the PC matrix were observed as crumpled and folded due to higher content of the GO. 


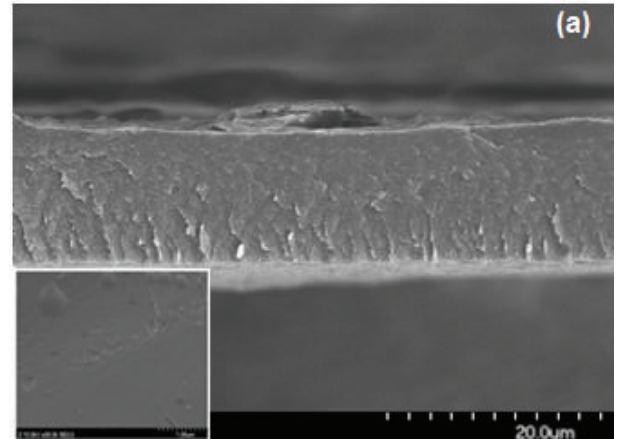

(a)

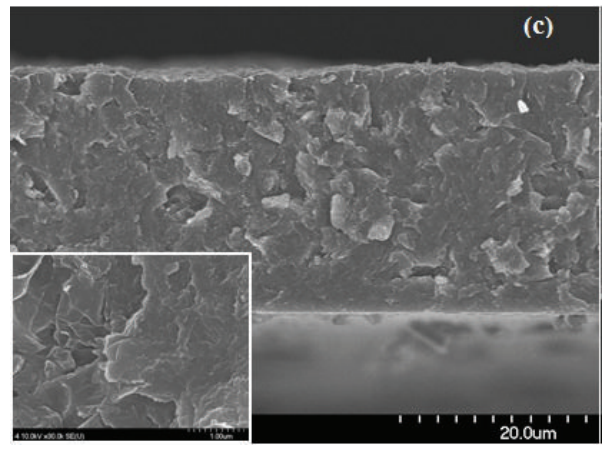

(c)

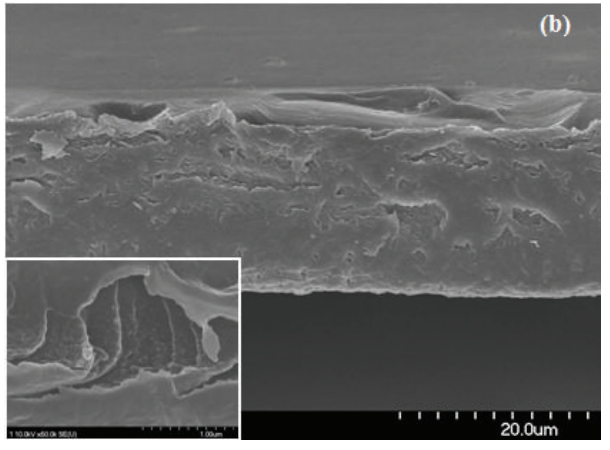

(b)

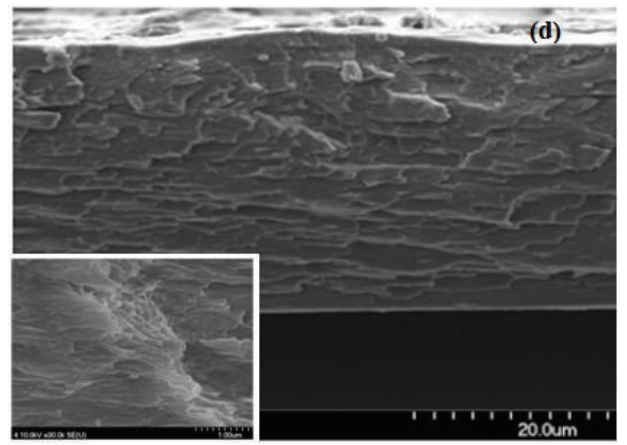

(d)

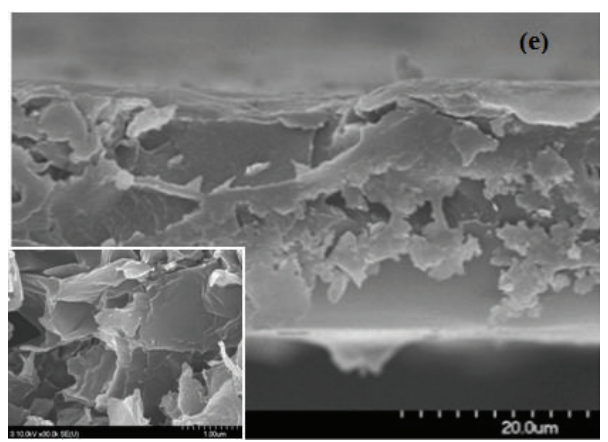

(e)

FIGURE 8: SEM micrographs: cross-sectional images of PC (a) and PC-GO 1, PC-GO 2, PC-GO 3, and PC-GO 4 (b-e) thin films.

3.5. Antibacterial Activities. Figures 9(a)-9(f) show the antibacterial activities of the GO, PC, and PC-GO samples against Gram-positive S. aureus (Figures 9(a), 9(c), and 9(e)) and Gram-negative E. coli (Figures 9(b), 9(d), and 9(f)). It was observed that the GO and PC-GO samples possessed growth inhibition zones for $S$. aureus and E. coli, owing to the antibacterial nature of GO. The inhibition zone was clearly identified at the edges of the samples, where the bacteria have not grown enough to be visible. A possible mechanism could be the following: the GO came into contact with the bacteria; it initiates the oxidation of glutathione (prominent cellular antioxidant) and the GO also acts as conducting bridge for extracting electrons from the glutathione and delivering them to the environment $[4,11,38]$. Notably, the pristine PC sample did not show any inhibition zones, due to the absence of GO. The antibacterial activities of the PC, GO, and PC-GO 3 samples against $S$. aureus and E. coli are shown in Figure 10. For S. aureus, the PC, GO, and PC-GO 3 exhibited inhibition zones of $\sim 0, \sim 3.4$, and $\sim 2.2 \mathrm{~mm}$, respectively. For E. coli, the inhibition zones were observed for the PC, GO, and PC-GO 3 around $\sim 0, \sim 3.3$, and $\sim 4.8 \mathrm{~mm}$, respectively.

\section{Conclusion}

In this work, graphene oxide reinforced polycarbonate based antibacterial and optically transparent thin films were 

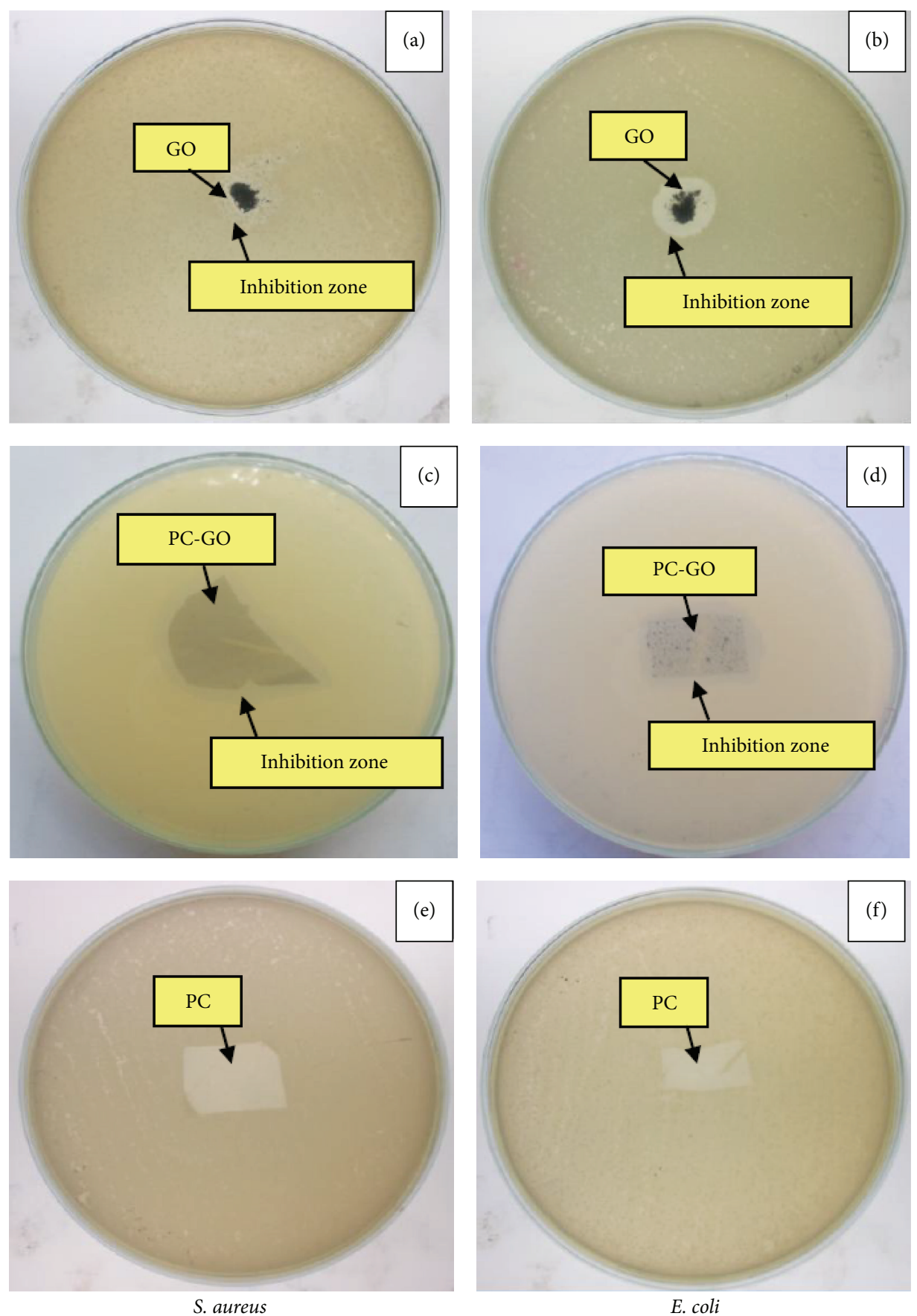

S. aureus

E. coli

Figure 9: Antibacterial activity of GO (a, b), PC-GO 3 (c, d), and PC (e, f) against S. aureus and E. coli.

fabricated by a facile technique. Thermal analysis and SEM micrographs confirmed the reinforcement of GO in the PC matrix. The agglomeration of GOs increased by increasing their concentration and the threshold limit of GO content in the PC matrix was $0.5 \%$. The GO and PC-GO films exhibited excellent bacteriostatic effect against $E$. coli and $S$. aureus. The antibacterial nature of the PC-GO films makes these materials promising candidates for use in biomedical devices and food packaging materials.

\section{Competing Interests}

The authors declare that there are no competing interests regarding the publication of this paper. 


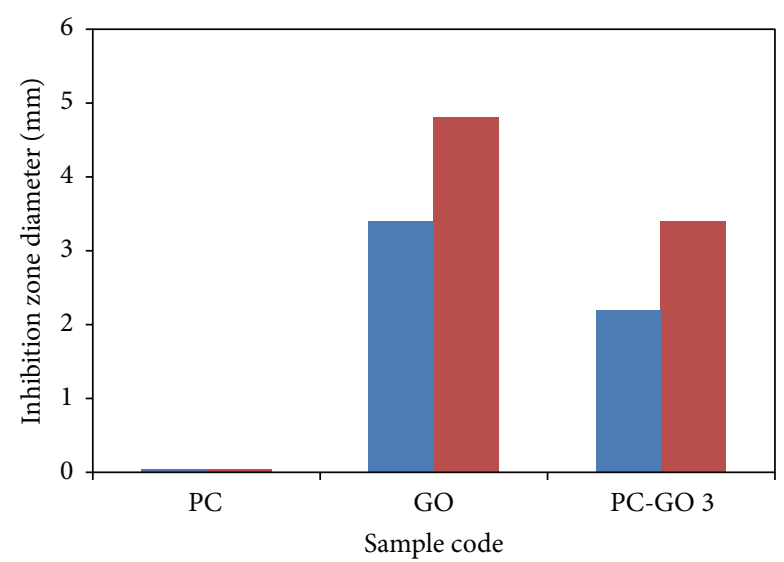

S. aureus

E. coli

FIGURE 10: Antibacterial activities of PC, GO, and PC-GO 3 samples against E. coli and S. aureus.

\section{References}

[1] L. Rizzello, R. Cingolani, and P. P. Pompa, "Nanotechnology tools for antibacterial materials," Nanomedicine, vol. 8, no. 5, pp. 807-821, 2013.

[2] A. J. Huh and Y. J. Kwon, “'Nanoantibiotics': a new paradigm for treating infectious diseases using nanomaterials in the antibiotics resistant era," Journal of Controlled Release, vol. 156, no. 2, pp. 128-145, 2011.

[3] S. Chernousova and M. Epple, "Silver as antibacterial agent: ion, nanoparticle, and metal," Angewandte Chemie-International Edition, vol. 52, no. 6, pp. 1636-1653, 2013.

[4] O. Akhavan and E. Ghaderi, "Toxicity of graphene and graphene oxide nanowalls against bacteria," ACS Nano, vol. 4, no. 10, pp. 5731-5736, 2010.

[5] W. Hu, C. Peng, W. Luo et al., "Graphene-based antibacterial paper," ACS Nano, vol. 4, no. 7, pp. 4317-4323, 2010.

[6] C. M. Santos, M. C. R. Tria, R. A. M. V. Vergara, F. Ahmed, R. C. Advincula, and D. F. Rodrigues, "Antimicrobial graphene polymer (PVK-GO) nanocomposite films," Chemical Communications, vol. 47, no. 31, pp. 8892-8894, 2011.

[7] X. An, H. Ma, B. Liu, and J. Wang, "Graphene oxide reinforced polylactic acid/polyurethane antibacterial composites," Journal of Nanomaterials, vol. 2013, Article ID 373414, 7 pages, 2013.

[8] Y.-Z. Tan, B. Yang, K. Parvez et al., "Atomically precise edge chlorination of nanographenes and its application in graphene nanoribbons," Nature Communications, vol. 4, article 2646, 2013.

[9] F. Hussain, M. Hojjati, M. Okamoto, and R. E. Gorga, "Review article: polymer-matrix nanocomposites, processing, manufacturing, and application: an overview," Journal of Composite Materials, vol. 40, no. 17, pp. 1511-1575, 2006.

[10] C. Yu and B. Li, "Morphology and properties of conducting polyvinyl alcohol hydrosulfate/graphite nanosheet composites," Journal of Composite Materials, vol. 42, no. 15, pp. 1491-1504, 2008.

[11] S. Some, S.-M. Ho, P. Dua et al., "Dual functions of highly potent graphene derivative-poly-l-lysine composites to inhibit bacteria and support human cells," ACS Nano, vol. 6, no. 8, pp. 7151-7161, 2012.
[12] D. W. Lin, C. J. Bettinger, J. P. Ferreira, C. L. Wang, and Z. Bao, "A cell-compatible conductive film from a carbon nanotube network adsorbed on poly-L-lysine," ACS Nano, vol. 5, no. 12, pp. 10026-10032, 2011.

[13] S. Some, J. S. Sohn, J. Kim et al., "Graphene-iodine nanocomposites: highly potent bacterial inhibitors that are bio-compatible with human cells," Science Reports, vol. 4, no. 6, Article ID 20015, 2016.

[14] O. Akhavan, E. Ghaderi, and A. Esfandiar, "Wrapping bacteria by graphene nanosheets for isolation from environment, reactivation by sonication, and inactivation by near-infrared irradiation," The Journal of Physical Chemistry B, vol. 115, no. 19, pp. 6279-6288, 2011.

[15] O. Akhavan and E. Ghaderi, "Photocatalytic reduction of graphene oxide nanosheets on $\mathrm{TiO}_{2}$ thin film for photoinactivation of bacteria in solar light irradiation," The Journal of Physical Chemistry C, vol. 113, no. 47, pp. 20214-20220, 2009.

[16] S. Liu, T. H. Zeng, M. Hofmann et al., "Antibacterial activity of graphite, graphite oxide, graphene oxide, and reduced graphene oxide: membrane and oxidative stress," ACS Nano, vol. 5, no. 9, pp. 6971-6980, 2011.

[17] M.-M. Zhang, H.-X. Yan, C. Gong, and F.-F. Zhang, "Hyperbranched polysiloxane functionalization of graphene oxide for improved mechanical properties of cyanate ester nanocomposites," Journal of Composite Materials, vol. 49, no. 8, pp. 939-948, 2015.

[18] D. J. Brunelle and M. R. Korn, Advances in Polycarbonates, American Chemical Society, Washington, DC, USA, 2005.

[19] J. Xu, E. Feng, and J. Song, "Renaissance of aliphatic polycarbonates: new techniques and biomedical applications," Journal of Applied Polymer Science, vol. 131, no. 5, Article ID 39822, 2014.

[20] S. H. Lee, K. Sung, T.-M. Chung et al., "Preparation of silver nanoparticles and antibiotic test of its polycarbonate films composite," Journal of Nanoscience and Nanotechnology, vol. 8, no. 9, pp. 4734-4737, 2008.

[21] L. Kessler, G. Legeay, A. Coudreuse et al., "Surface treatment of polycarbonate films aimed at biomedical application," Journal of Biomaterials Science, Polymer Edition, vol. 14, no. 10, pp. 11351153, 2003.

[22] K. Vani, S. Thomas, V. Prabhawathi, T. Boobalan, S. N. Sawant, and M. Doble, "In vitro biocompatiblity of modified polycarbonate as a biomaterial," Colloids and Surfaces B: Biointerfaces, vol. 108, pp. 191-198, 2013.

[23] R. Glaum, M. Wiedmann-Al-Ahmad, U. Huebner, and R. Schmelzeisen, "Tissue engineering of composite grafts: cocultivation of human oral keratinocytes and human osteoblastlike cells on laminin-coated polycarbonate membranes and equine collagen membranes under different culture conditions," Journal of Biomedical Materials Research-Part A, vol. 93, no. 2, pp. 704-715, 2010.

[24] W. S. Hummers Jr. and R. E. Offeman, "Preparation of graphitic oxide," Journal of the American Chemical Society, vol. 80, no. 6, p. 1339, 1958.

[25] S. Deniz, "Characteristics of polycarbonate membranes with polyethylene glycol prepared via dry/wet-phase inversion methods," Desalination, vol. 200, no. 1-3, pp. 42-43, 2006.

[26] S. Sodha, K. Wall, S. Redenti, H. Klassen, M. J. Young, and S. L. Tao, "Microfabrication of a three-dimensional polycaprolactone thin-film scaffold for retinal progenitor cell encapsulation," Journal of Biomaterials Science, Polymer Edition, vol. 22, no. 4-6, pp. 443-456, 2011. 
[27] J. R. Potts, S. Murali, Y. Zhu, X. Zhao, and R. S. Ruoff, "Microwave-exfoliated graphite oxide/polycarbonate composites," Macromolecules, vol. 44, no. 16, pp. 6488-6495, 2011.

[28] J. H. Jorgensen, S. A. Crawford, L. C. Fulcher et al., "Multilaboratory evaluation of disk diffusion antimicrobial susceptibility testing of Neisseria meningitidis isolates," Journal of Clinical Microbiology, vol. 44, no. 5, pp. 1744-1754, 2006.

[29] B. Maria, W. Kinga, and Z. Szczepan, "Chitosan-based ultrathin films as antifouling, anticoagulant and antibacterial protective coatings," Journal of Biomaterial Science Polymer Edition, vol. 23, pp. 1963-1980, 2012.

[30] I. A. Popov, K. V. Bozhenko, and A. I. Boldyrev, "Is graphene aromatic?” Nano Research, vol. 5, no. 2, pp. 117-123, 2012.

[31] Y. Zhu, S. Murali, W. Cai et al., "Graphene and graphene oxide: synthesis, properties, and applications," Advanced Materials, vol. 22, no. 35, pp. 3906-3924, 2010.

[32] A. Nodera and T. Kanai, "Thermal decomposition behavior and flame retardancy of polycarbonate containing organic metal salts: effect of salt composition," Journal of Applied Polymer Science, vol. 94, no. 5, pp. 2131-2139, 2004.

[33] D. Han, L. Yan, W. Chen, and W. Li, "Preparation of chitosan/graphene oxide composite film with enhanced mechanical strength in the wet state," Carbohydrate Polymers, vol. 83, no. 2, pp. 653-658, 2011.

[34] B. A. Sweileh, Y. M. Al-Hiari, M. H. Kailani, and H. A. Mohammad, "Synthesis and characterization of polycarbonates by melt phase interchange reactions of alkylene and arylene diacetates with alkylene and arylene diphenyl dicarbonates," Molecules, vol. 15, no. 5, pp. 3661-3682, 2010.

[35] A. M. Pandele, M. Ionita, L. Crica, S. Dinescu, M. Costache, and H. Iovu, "Synthesis, characterization, and in vitro studies of graphene oxide/chitosan-polyvinyl alcohol films," Carbohydrate Polymers, vol. 102, no. 1, pp. 813-820, 2014.

[36] Z. Pan, Z. Hu, Y. Shi, Y. Shen, J. Wang, and I.-M. Chou, "Depolymerization of polycarbonate with catalyst in hot compressed water in fused silica capillary and autoclave reactors," RSC Advances, vol. 4, no. 38, pp. 19992-19998, 2014.

[37] S. Eigler and A. Hirsch, "Chemistry with graphene and graphene oxide-challenges for synthetic chemists," Angewandte Chemie - International Edition, vol. 53, no. 30, pp. 77207738, 2014.

[38] L. Masip, K. Veeravalli, and G. Georgiou, "The many faces of glutathione in bacteria," Antioxidants \& Redox Signaling, vol. 8, no. 5-6, pp. 753-762, 2006. 

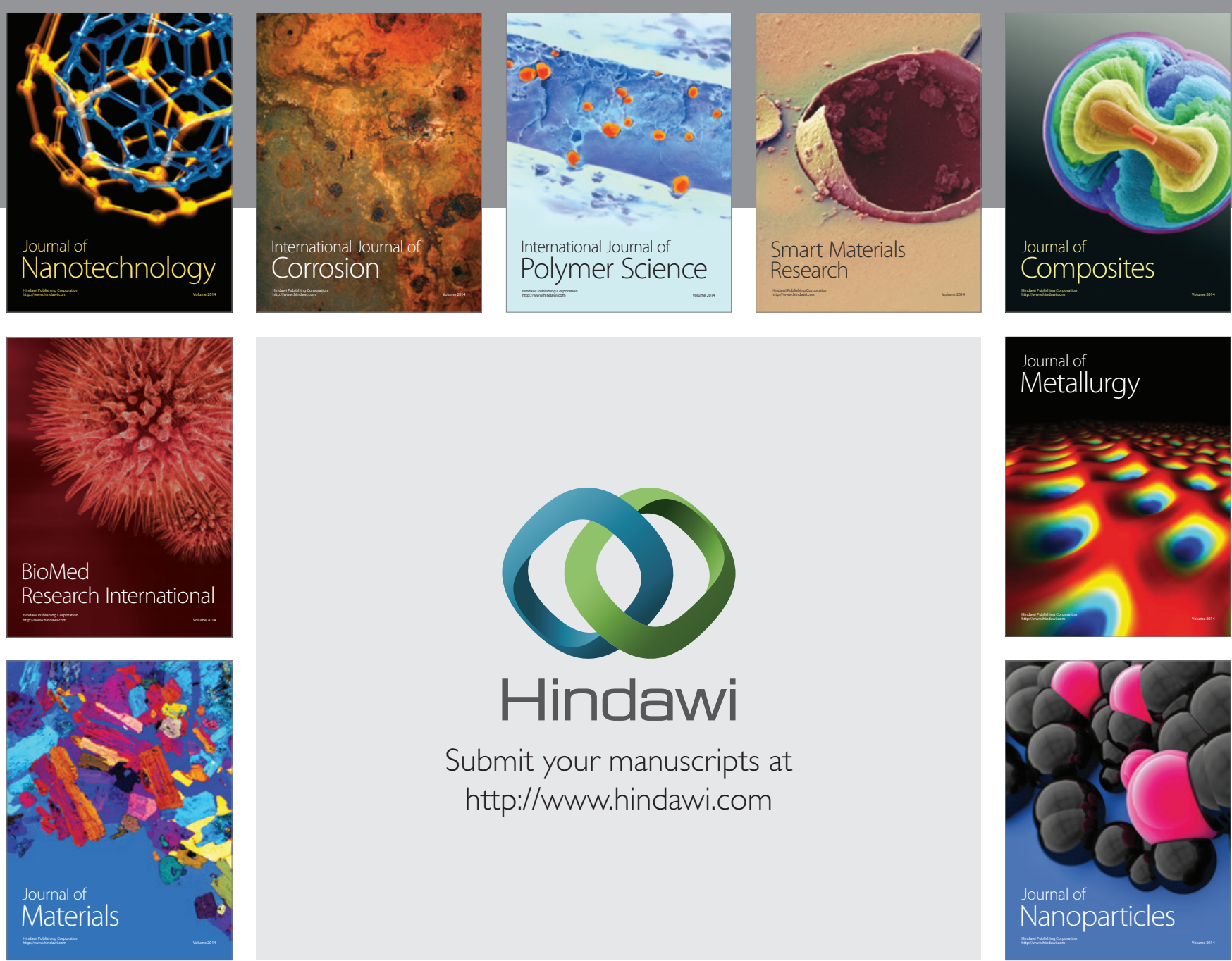

\section{Hindawi}

Submit your manuscripts at

http://www.hindawi.com

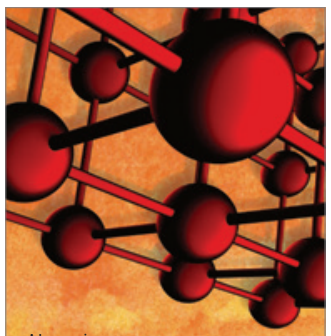

Materials Science and Engineering
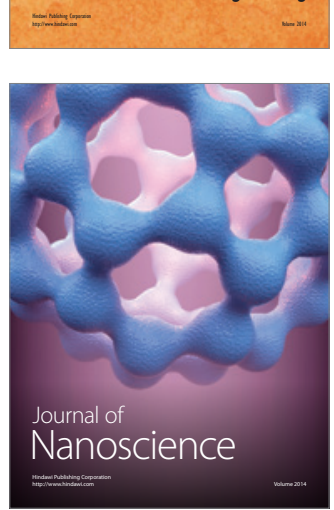
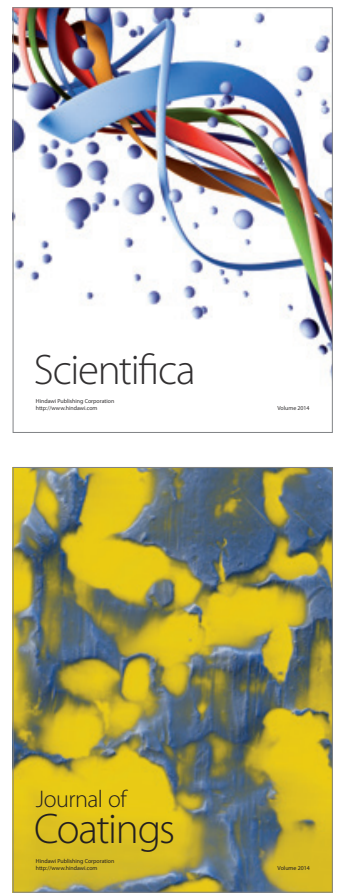
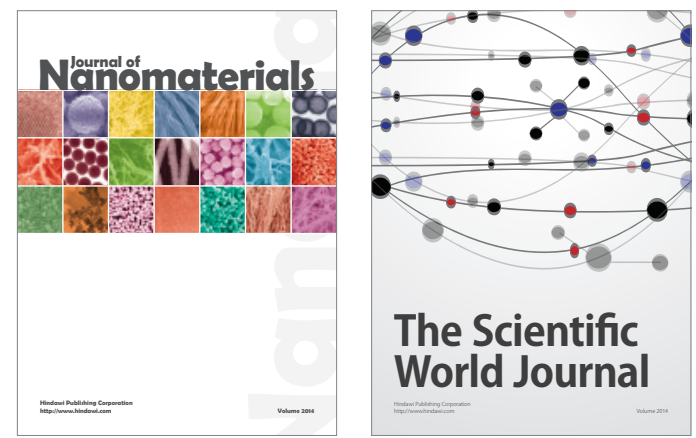

The Scientific World Journal
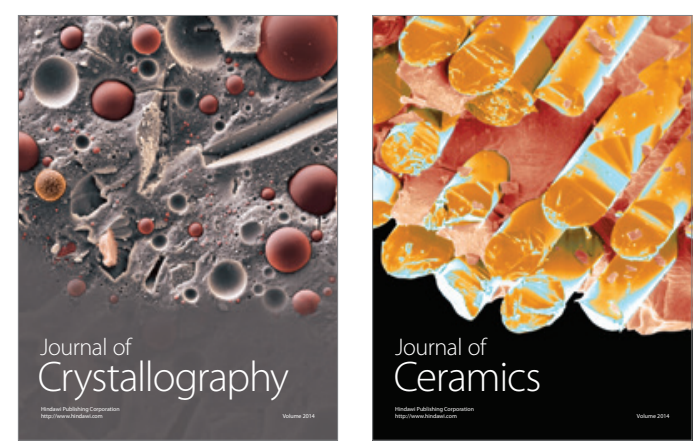
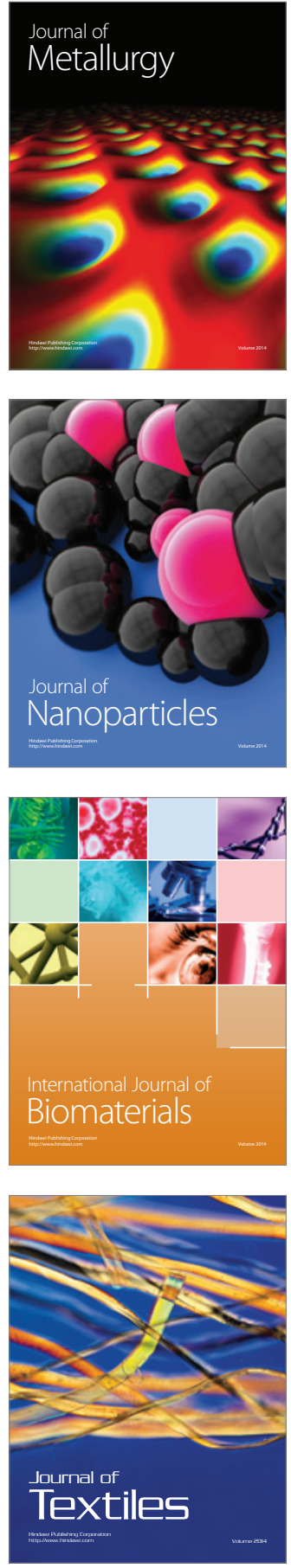